\title{
CES
}

COOPERATIVISMO E ECONOMÍA SOCIAL

Núm. 41 (2018-2019), páxs. 293-298

ISSN: $1130-2682$

\section{A ANOTACIÓN Á LEY 5/2018, DE 19 DE JUNIO, POLA QUE SE MODIFICA A LEY 14/2011, DE 23 DE DICIEMBRE, DE SOCIEDADES COOPERATIVAS ANDALUZAS}

ANOTATION TO LAW 5/2018, OF 19 JUNE, MODIFICATION OF LAW 14/2011, OF 23 DECEMBER, OF ANDALUSIA COOPERATIVES SOCIETIES

Francisco José ToRres PÉreZ*

* Profesor Titular de Derecho mercantil, Universidade de Vigo. Dirección de correo electrónico: ftorres@uvigo.es. 


\section{RESUMEN}

A lexislación andaluza de sociedades cooperativas é unha das máis detalladas do noso Estado. Non obstante, en xuño do 2018 tense modificado fundamentalmente cos seguintes obxectivos: flexibilizar o proceso de constitución das cooperativas e a estrutura do órgano de administración; introducir certas variacións no réxime económico; e, principalmente, introducir cambios na disciplina das seccións de crédito. Así mesmo, as modificacións afectaron a aspectos relacionados coas infraccións e as oportunas sancións.

Palabras chave: Lei Cooperativas Andalucía, Constitución, Órgano de administración, infraccións e sancións.

\section{ABSTRACT}

Andalusian legislation on cooperative societies is one of the most detailed in our State. However, in June 2018, it has been fundamentally modified with the following objectives: to make the cooperative constitution process and the structure of the administrative body more flexible; to introduce certain variations in the economic regime; and, mainly, to add changes in the discipline of the credit sections. In addition, the changes have affected aspects related to infractions and the appropriate sanctions.

Keywords: Andalusian Cooperative Law, Company formation, Administrative Body, Infractions and Sanctions. 
$\mathrm{O}$ día 2 de xullo de 2018 publicábase no "Boletín Oficial de la Junta de Andalucía" a "Ley 5/2018, de 19 de junio, pola que se modificaba a Ley 14/2011, de 23 de diciembre, de Sociedades Cooperativas Andaluzas" (en adiante LSCA). A norma entrou en vigor o día seguinte da súa publicación no BOJA e, ademais, publicouse no BOE do 30 de xullo de 2018.

De inicio é preciso salientar que o corpo normativo no eido das Cooperativas na Comunidade Autónoma de Andalucía é o mais extenso do panorama lexislativo existente no noso Estado. De feito, a LSCA antes citada foi desenvolvida polo Decreto 123/2014, de 2 de setembro polo que se aprobou o seu Regulamento. Un regulamento completo e detallado e próximo aos 200 artigos que viña a completar o xa de por si extenso articulado da "Ley 14/2011". Por tanto, tal e como se deduce das datas de aprobación de tales normas, o marco legal vixente en Andalucía xa estaba adaptado as modificacións que de forma gradual se realizaron no ámbito das cooperativas e coa finalidade de adaptar a normativa de tales sociedades as esixencias da normas internacionais de contabilidade.

Non obstante, tamén é necesario indicar que a diferencia doutros lexislativos autonómicos, en Andalucía non se tiña aprobado unha norma específica sobre cooperativas de crédito, estando disciplinadas as denominadas seccións de crédito na propia "Ley 14/2011".

Avanzadas estas cuestións, temos que sinalar que as modificacións operadas pola "Ley 5/2018" aquí anotada, céntranse no réxime de constitución (ii), en modificacións puntuais na organización do órgano de administración e no rexime e económico (iii), e, por último, con maior detalle no réxime de infraccións e sancións (iv).

\section{II}

No que atinxe ao réxime de constitución, a principal novidade introducida pola "Ley $5 / 2018$ " e a variación do número mínimo de persoas socias. Nunha liña seguida por outros lexisladores autonómicos, a nova redacción do artigo 10 da LSCA contempla a posibilidade de constituír cooperativas de primeiro grao con dúas persoas socias. A xustificación desta medida situase polo lexislador andaluz nunha "nova" medida de flexibilidade na constitución deste tipo de sociedades debido aos beneficiosos efectos que dita solución legal ten implicado noutras comunidades autónomas o que, segundo o expresado na Exposición de Motivos da norma aquí anotada, incide na creación de emprego e na marcada responsabilidade social deste tipo de sociedades. Ao respecto, simplemente destacar a inexisten- 
cia de dados estatísticos concluíntes sobre esta aseveración do lexislador andaluz nin que esta sexa a medida seguida por todos os lexisladores. De facto, normas recentes como a nova lei de Estremadura de cooperativas (art. $6^{\circ}$ da Lei 9/2018, de 30 de outubro, de sociedades cooperativas de Estremadura) declaran como regra xeral o tradicional número mínimo de 3 persoas socias para constituír unha cooperativa de primeiro grao. Tamén neste punto, e sen ánimo de detalle, temos que salientar que outras normas circunscriben a constitución por dúas persoas ás cooperativas de traballo asociado -por exemplo o art. 9.3 do Decreto Lexislativo 2/2015, de 15 de maio, pola que se aprobou o texto refundido da Lei de Cooperativas da Comunidade Valenciana-. En relación co réxime constitutivo tense variado o art. 104.1 no relativo á tipoloxía de persoas socias nas cooperativas agrarias. En concreto regúlanse os requisitos de acceso das denominadas explotacións agrarias de titularidade compartida no que se refire a acreditación da persoa física que exercerá a súa representatividade na cooperativa.

Así mesmo, en relación coa inscrición de actos no rexistro de cooperativas, modificouse o art. 119.1. Neste caso, o lexislador andaluz parte da diferenciación entre efectos constitutivos da inscrición de certos actos expresamente citados (constitución, modificación de estatutos, fusión, escisión, etc.), e declarativos noutros supostos (non producindo efectos fronte a terceiros de boa fe, ata a súa inscrición en rexistro). Con todo, neste artigo declarase que a intervención notarial na documentación a presentar no rexistro, terá por regra xeral carácter potestativo.

\section{III}

Outra das novidades da "Ley 5/2018" afecta á estrutura do órgano de administración das cooperativas. Neste punto, declárase como carácter xeral que o órgano de administración nas cooperativas será o Consello Reitor para engadir (art. 36.1, II) que en sociedades que teñan un número igual ou inferior a 10 persoas socias, estatutariamente poderá preverse outros modos de organizar a sociedade, isto é: Administración única ou Administración solidaria. No caso das cooperativas con dúas persoas socias terá que preverse nos estatutos obrigatoriamente dita atribución (art. 42.1). Tamén compre subliñar que, segundo se especifica no art. 36.2, os estatutos poderán atribuír a Asemblea Xeral a posibilidade de optar por calquera modo de organizar a sociedade sen necesidade de modificación estatutaria si ben axustándose a inscrición rexistral ao procedemento que se determine regulamentariamente.

Seguindo coas novidades no ámbito da organización, o art. 47 contempla a posibilidade de prever nos estatutos unha dirección integrada por unha ou varias persoas. Non obstante, no caso específico das sociedades cooperativas de crédito ou naquelas cooperativas que teñan seccións de crédito, será necesaria a designación dun director/a xeral con dedicación permanente ou órgano equivalente. En 
tales supostos tamén prevese a posibilidade de que podan coexistir unha dirección xeral da cooperativa cunha específica da sección de crédito correspondente. A posibilidade de elixir un "órgano equivalente" ven avalada polo art. 12.2 que tamén foi variado e no se que se fala que, no caso das seccións, poderase elixir un órgano colexiado (o denominado Consello de Sección) ou unipersoal (a chamada Administración da Sección).

Ao fío desta modificación na organización da estrutura do órgano de administración, variouse a lexitimación activa para impugnar os acordos do Consello Reitor. Neste punto, o art. 41 completa o previsto no art. 35 -que contempla a impugnación de acordos da Asemblea Xeral-. Neste senso, ademais de estar lexitimadas aquelas persoas que fixeran constar no acta a oposición ao acordo, as non asistentes e as que foran ilexítimamente privadas de emitir o voto, os acordos anulables do Consello Reitor poderanse impugnar por un número de persoas que represente ao menos: o $10 \%$ nas cooperativas de mais de mil, $15 \%$ nas de mais de 500 , e $20 \%$ nas restantes. No caso de acordos nulos, poderanse impugnar por calquera persoa socia.

No ámbito económico, tan so dúas breves referencias a sendas modificacións incorporadas pola norma aquí anotada. No art. 54.3 segue contemplándose unha limitación ao importe máximo que pode realizar cada persoa socia, en concreto o $45 \%$ do capital social en caso de cooperativas de primeiro grao e coa consabida excepción nas aportacións por entidades públicas. Non obstante, precísase que no caso de que tal cooperativa este integrada por dúas persoas socias, tal importe poderá chegar ata o $65 \%$ do capital social. A outra modificación afecta aos xuros que devengan as achegas ao capital social. Segundo a nova redacción do art. 57.1, no caso de que tales achegas foran feitas por unha persoa socia, a contía dos xuros -determinada estatutariamente ou pola Asemblea ou polo órgano que as determine no caso das achegas voluntarias-, non poderá superar 6 puntos do xuro legal, e no caso de facerse a achega por unha "persoa inversora" tal límite situaríase en 8 puntos.

\section{IV}

Finalmente, na norma aquí anotada e ao fío da revisión da normativa aplicable ás seccións de crédito, introdúcense importantes modificacións no réxime de inspección, infraccións e sancións da LSCA. Neste punto, simplemente sinalar que no art. 120.1 declárase que a función inspectora nas seccións de seccións de crédito corresponde especificamente á Consellería competente en materia de política financeira. A partir desa declaración, defínense as competencias do órgano inspector (art. 122.2) e, como avanzamos, faise unha revisión certamente pormenorizada das infraccións (art. 123) partindo da típica clasificación entre infraccións leves, 
graves e moi graves (neste último punto certamente detallada -art. 123.4 aptos. a)t)- se a analizamos comparativamente con respecto a outras normas autonómicas).

No que atinxe ás contías das sancións tamén realízanse modificacións engadindo unha regra específica para infraccións moi graves cometidas en materia de seccións de crédito. En particular, para aqueles casos nos que tales infraccións sexan susceptibles de provocar unha perda total ou parcial dos depósitos das persoas socias ou cando concorra reincidencia na comisión de infraccións, poderá sancionarse coa baixa de oficio da sección de crédito e prohibición de desenvolver a súa actividade. Por último, tamén en materia de sancións, modifícanse os prazos de prescrición así como as causas de interrupción de tales prazos (art. 125.2). 